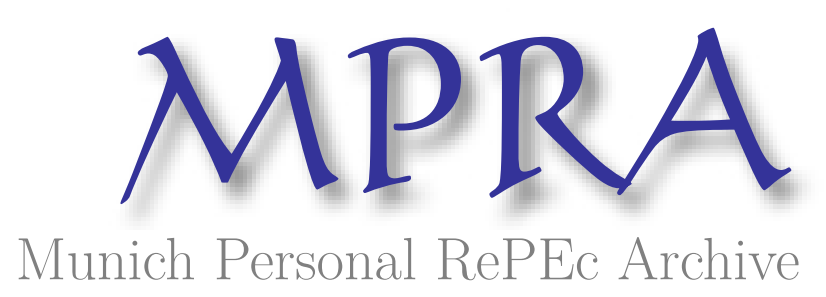

\title{
Testing for Bubbles in Stock Markets with Irregular Dividend Distribution
}

Caspi, Itamar and Graham, Meital

Bank of Israel, Bar-Ilan University, Hebrew University of Jerusalem

24 April 2017

Online at https://mpra.ub.uni-muenchen.de/82261/

MPRA Paper No. 82261, posted 30 Oct 2017 11:19 UTC 


\title{
TESTING FOR BUBBLES IN STOCK MARKETS WITH IRREGULAR DIVIDEND DISTRIBUTION*
}

\author{
Itamar Caspi ${ }^{\dagger 1,2}$ and Meital Graham ${ }^{\ddagger 1,3}$ \\ ${ }^{1}$ Bank of Israel \\ ${ }^{2}$ Bar-Ilan University \\ ${ }^{3}$ Hebrew University of Jerusalem
}

October 29, 2017

\begin{abstract}
Recursive right-tailed unit root tests have recently become a popular tool to test the existence of stock price bubbles. These tests require continuous data on dividend distribution that is not always available, in particular when it comes to sectoral indexes or individual stocks. In this paper we show that it is possible to circumvent this problem by applying the test to an equity bubble using the book-to-market ratio. We illustrate our framework by testing for a bubble in the Israeli stock market, where data on continuous dividend distribution are uncommon.
\end{abstract}

Keywords: Bubbles, stock markets, book-to-market, explosive root, GSADF test, Israel JEL Classification: $C_{12}, C_{15}, G_{12}, G_{15}$

\footnotetext{
${ }^{*}$ The views expressed herein are solely those of the authors and do not necessarily reflect the views of the Bank of Israel, or any of its staff. We would like to thank Michael Kahn, Edward Offenbacher, Sigal Ribon, Nathan Sussman as well as seminar participants at the Bank of Israel for their helpful discussions and comments. All errors and omissions are our own responsibility.

${ }^{\dagger}$ Email: i tamar.caspi@boi .org.il. (Corresponding author.)

‡Email: meital.graham@boi .org.il
} 


\section{INTRODUCTION}

Asset price bubbles, and stock price bubbles in particular, have gained a tremendous amount of attention both in public discussion and in academia. Recent empirical work suggests that such bubbles might have devastating consequences for the economy, especially when coupled with a credit boom (Jordà et al., 2015, 2016). The most recent example of such a phenomenon is the "Dot-com" bubble of the 1990s during which advanced economies' stock prices, mostly related to the rapidly growing Internet sector, surged, only to witness a sharp reversal during the late 1990s-early 2000s. As its name suggests, this boom and bust period in Internet stock prices is perceived as a bubble, suggesting that the surge in prices was mostly speculative in nature and unrelated to fundamentals. Nonetheless, at least in academia, the mere existence of bubbles, let alone the ability to detect them in real time, remains in debate.

In recent years, new econometric methods that aim at testing the existence and prevalence of bubble periods, attracted a great deal of attention in the literature. One prominent strand of this literature, initiated by Phillips et al. (2011) and Phillips et al. (2015), applies time series methods in order to detect and date-stamp bubbles. The key innovation is the use of recursive right-tailed unit root tests. These exhibit good power properties against the alternative of a bubble, are often used as a real time monitoring device for bubbles (e.g., Homm and Breitung, 2012), and have many applications in various markets - from stocks through commodities to housing markets.

In order to test for a bubble in stock prices, the literature initiated by Phillips et al. (2011) usually uses data on prices and dividends and tests whether the former is explosive while the latter is not or whether the ratio between them is explosive. Examples include Phillips et al. (2011) who investigate the Nasdaq composite price index and the Nasdaq composite dividend; Phillips et al. (2015) who analyze the S\&P 500 price-to-dividend ratio; Homm and Breitung (2012) who test the Nikkei 225, FTSE 100, Hang Seng, and Shanghai indexes ${ }^{1}$; Christensen and Andersen (2015) who test price-to-dividend ratios from a panel of 23 countries; and Chang et al. (2016) who test the Brazil, Russia, India, China and South Africa (BRICS) stock price-dividend ratios. ${ }^{2}$ The above examples highlight the fact that testing for

${ }^{1}$ Homm and Breitung (2012) note that dividend series were only available for the S\&P 500 and the Hang Seng.

${ }^{2}$ One can also find applications of the Phillips et al. (2015) test for bubbles for other types of assets, such as houses and bonds (e.g., Caspi (2016) and Phillips and Shi (2017)), as well as to oil and commodities markets (e.g., Alexakis et al. (2017) and Caspi et al. (2015)). 
the existence of bubbles is deeply dependent on the availability of a continuous dividend series. Hence, using these tests to determine the existence of a bubble in individual stocks or markets where the distribution of dividends is not continuous are bubbly is challenging.

The purpose of this paper is to provide a framework that allows the implementation of the Phillips et al. (2011) and Phillips et al. (2015) tests for bubbles in cases where data on dividends are discontinuous or even missing. In particular, instead of testing for explosiveness in prices and dividends (or in the price-to-dividend ratio), we apply the standard test to the more readily available book-to-market ratio data, and provide a theoretical justification, based on the dynamic book-tomarket model (Vuolteenaho, 1999, 2002). Accordingly, explosive behavior in the book-to-market ratio may serve as evidence for an asset price bubble.

We illustrate the use of our proposed method by applying the tests for bubbles to data from the Israeli stock market (July 1996 to November 2014). The Israeli stock market is chosen due to the usual tendency of this market not to distribute dividends continuously. We find no evidence of bubble periods in any of the sectors we examine. Our empirical application in this study is related to a series of recent studies that ask whether leading equity indices around the world exhibit bubble behavior.

The article is structured as follows. Section 2 describes the dynamic book-tomarket model and provides the theoretical justification for using it to tests for bubbles. Section 3 briefly describes the bubble detection methodology. Section 4 illustrates our proposed framework by an empirical application to Israeli book-tomarket data, and Section 5 concludes.

\section{Bubbles AND THE BOOK-TO-MARKET RATIO}

According to the standard present-value model, the general solution to the price of an asset is given by

$$
P_{t}=\mathbb{E}_{t} \sum_{j=1}^{\infty}(1+R)^{-1} D_{t+j+1}+B_{t}
$$

where $P_{t}$ denotes the price of an asset at time $t, D_{t}$ the dividend, $R$ a constant discount rate, $\mathbb{E}_{t}$ the mathematical expectation conditioned on information at time 
$t$, and $B_{t}$ the rational bubble component that satisfies

$$
\mathbb{E}_{t}\left[B_{t+1}\right]=(1+R) B_{t}
$$

The first component on the right-hand side of Equation 1 is the "fundamental value." When no bubble exists, i.e., when $B_{t}=0$, the price reflects the fundamental value. Conversely, $B_{t} \neq 0$ describes a situation where investors are willing to pay a premium over the fundamental value. According to condition (2), paying such a premium is justified since it is expected to increase at a rate of $1+R$ over the next period.

Since the discount rate is strictly positive, Equation (2) implies that the $B_{t}$ follows an explosive path. Moreover, if an explosive bubble is present it will eventually dominate the stochastic behavior of $P_{t}$, which will be explosive as well. In effect, the explosiveness feature of the bubble component provides an identifying restriction that can be used to empirically test for the presence of a bubble. In particular, finding that $P_{t}$ is explosive while $D_{t}$ is not may serve as evidence for the presence of a bubble.

Testing for a bubble in equities for which dividends data are discontinuous is technically impossible To tackle this problem, we suggest using the book-to-market model of Vuolteenaho (1999, 2002), that starts off with the identity

$$
V_{t}-V_{t-1}=X_{t}-D_{t}
$$

where $V_{t}$ denotes the book value at time $t, X_{t}$ the earnings, and $D_{t}$ the dividends. According to this identity the change in book value from time $t-1$ to $t$ equals earnings less dividends.

Vuolteenaho continues with the definition of the log book-to-market ratio

$$
v m_{t}=\log \left(V_{t} / M_{t}\right)=v_{t}-m_{t}
$$

where $M_{t}$ denotes the market equity value at time $t$, and derives an expression for the log book-to-market ratio that is analogous to the dynamic Gordon growth model (Campbell and Shiller, 1988):

$$
v m_{t}=k_{t}+\mathbb{E}_{t} \sum_{j=1}^{\infty} \rho^{j} r_{t+j+1}-\mathbb{E}_{t} \sum_{j=1}^{\infty} \rho^{j}\left(r_{t+j+1}^{e}-r_{t+j+1}^{f}\right)+b_{t},
$$

where $r_{t}$ denotes the log gross extra return over market valuation at time $t, r_{t}^{e}$ the 
log gross return on equity (ROE), $r_{t}^{f}$ the log gross risk-free return, $k_{t}$ a function of the constants around which the log-linear approximation is made, and $b_{t}$ the bubble component. ${ }^{3}$

Analogously to Equation (1), the first component on the right-hand side of Equation (5) is the "fundamental (log) book-to-market ratio" since it is a function of the fundamentals that determine the fundamental value of an equity, namely, $\mathrm{ROE}$, risk-free return, and expected risk premiums. In turn, the second term on the right-hand side of Equation (5) represents the rational bubble component. Accordingly, the existence of a bubble is consistent with a situation where the log of the market value of a firm departs explosively from its log book value.

\section{ECONOMETRIC FRAMEWORK}

Phillips et al. (2015, hereinafter, PSY) develop a bubble detection and date-stamping strategy that is based on tests for an explosive root. The authors set the datagenerating process for the null hypothesis as a random walk with a marginally negligible drift:

$$
H_{0}: y_{t}=d_{T}+y_{t+1}+\varepsilon_{t},
$$

where $d_{T}=d T^{-\eta}$ with $\eta>0.5$. The alternative hypothesis is expressed as process with a mildly explosive root in the sense of Phillips and Magdalinos (2007):

$$
H_{1}: y_{t}=\delta_{T} y_{t-1}+\varepsilon_{t},
$$

where $\delta_{T}=1+c T^{-\theta}$ with $c>0$ and $0<\lambda<1$.

The PSY methodology involves a recursive estimation of the regression model

$$
\Delta y_{t}=\alpha_{\lambda_{1}, \lambda_{2}}+\rho_{\lambda_{1}, \lambda_{2}} y_{t-1}+\sum_{j=1}^{p-1} \gamma_{\lambda_{1}, \lambda_{2}}^{i} \Delta y_{t-i}+\varepsilon_{t}
$$

and calculation of the $t$-statistic

$$
\operatorname{ADF}_{\lambda_{1}, \lambda_{2}}=\frac{\hat{\rho}_{\lambda_{1}, \lambda_{2}}}{\operatorname{S.E.}\left(\hat{\rho}_{\lambda_{1}, \lambda_{2}}\right)}
$$

where the sub- and superscripts $\lambda_{1}$ and $\lambda_{2}$ attached to each coefficient denote the

${ }^{3}$ Here, we depart from Vuolteenaho $(1999,2002)$, who explicitly excludes the existence of a bubble by imposing the "value relevance" assumption that $v_{t}$ and $m_{t}$ are cointegrated with a cointegrating vector $(1-1)$. 
fraction of the sample these parameters are estimated with, such that $0 \leq \lambda_{1}<$ $\lambda_{2} \leq 1$. For example, $\alpha_{\lambda_{1}, \lambda_{2}}$ is the constant term for the regression that is estimated between $\left\lfloor T \lambda_{1}\right\rfloor$ and $\left\lfloor T \lambda_{2}\right\rfloor$, where $\lfloor\cdot\rfloor$ is the floor function.

According to PSY, the test statistic used to test the null hypothesis of "no bubble" is the Generalized Sup ADF (GSADF) test statistic, which is the supremum value of the sequence of $\mathrm{ADF}_{\lambda_{1}, \lambda_{2}}$ test statistics:

$$
\operatorname{GSADF}\left(\lambda_{0}\right)=\sup _{\substack{\lambda_{2} \in\left[\lambda_{0}, 1\right] \\ \lambda_{1} \in\left[0, \lambda_{2}-\lambda_{0}\right]}}\left\{\operatorname{ADF}_{\lambda_{1}, \lambda_{2}}\right\}
$$

The null is rejected when the value of the GSADF statistic exceeds the relevant critical value.

Conditioned on the null hypothesis being rejected, the estimates of the bubble period are given by

$$
\begin{aligned}
& \hat{\lambda}_{e}=\inf _{\lambda_{2} \in\left[\lambda_{0}, 1\right]}\left\{\lambda_{2}: B S A D F_{\lambda_{2}}\left(\lambda_{0}\right)>c v_{r_{2}}^{\beta_{T \lambda_{2}}}\right\} \\
& \hat{\lambda}_{f}=\inf _{\lambda_{2} \in\left[\hat{\lambda}_{e}, 1\right]}\left\{\lambda_{2}: B S A D F_{\lambda_{2}}\left(\lambda_{0}\right)<c v_{\lambda_{2}}^{\beta_{T \lambda_{2}}}\right\}
\end{aligned}
$$

where $\operatorname{BSADF}\left(r_{0}\right)$ for $r_{2} \in\left[r_{0}, 1\right]$ is the backward sup ADF statistic defined as

$$
\operatorname{GSADF}\left(\lambda_{0}\right)=\sup _{\lambda_{2} \in\left[\lambda_{0}, 1\right]}\left\{B S A D F_{\lambda_{2}}\left(\lambda_{0}\right)\right\}
$$

and $c v_{\lambda_{2}}^{\beta_{T}}$ is the $100\left(1-\beta_{T}\right) \%$ critical value of the sup ADF statistic based on $\left[T \lambda_{2}\right]$ observations.

\section{EMPIRICAL APPLICATION}

In this section we illustrate the use of our proposed method with an empirical application to the Israeli stock market, where discontinuous dividend distribution is common and where data on book-to-market ratios is readily available. To be able to fit the dynamic book-to-market model we define the book-to-market ratio as the ratio of a company's market valuation to its equity, where equity is defined as the surplus shareholders are entitled to if the firm realizes all its assets and pays off all its liabilities. 


\subsection{Data and specifications}

In our implementation we use monthly data on seven sectoral book-to-market ratios, as well as the aggregate book-to-market ratio for the period July 1996 to November 2014. ${ }^{4}$ The sample in our possession is composed of 583 companies (average during the sample period) that belong to seven sectors: Insurance, Banking, Investment and Holdings, Oil and Gas Exploration, Commerce and Services, Real Estate and Construction, and Manufacturing.

Table 1 provides the sample mean for market value, book value and book-tomarket ratio (along with its standard deviation) for each sector and the aggregate during the sample period. ${ }^{5}$ Sizable differences are found between the sectors in both the average size and the standard deviation of the ratio, as can be seen in Figure 1, which plots the time path of the sectoral book-to-market ratios. The Oil and Gas Exploration sector had both the highest average ratio and the largest S.D. (avg. 2.67, maximum 8.14).

Table 1

Summary statistics by sectors

\begin{tabular}{lcccc}
\hline Sector & $\begin{array}{c}\text { Market value } \\
\text { (NIS billion) } \\
(1)\end{array}$ & $\begin{array}{c}\text { Book value } \\
\text { (NIS billion) } \\
(2)\end{array}$ & $\begin{array}{c}\text { Book-to-market } \\
\text { ratio } \\
(3)\end{array}$ & (std. err.) \\
\hline Insurance & 14.9 & 10.9 & 1.4 & $(4)$ \\
Banking & 50.4 & 62.6 & 0.8 & $($ o.4) \\
Investment and holdings & 48.4 & 60.8 & 0.7 & $($ o.2) \\
Oil and gas exploration & 12.8 & 3.1 & 2.6 & $(1.9)$ \\
Commerce and services & 56.6 & 32.3 & 1.7 & $(0.5)$ \\
Real estate and construction & 35.4 & 53.5 & 0.7 & $(0.2)$ \\
Manufacturing & 197.0 & 86.0 & 2.3 & $(0.6)$ \\
\cline { 2 - 6 } & 419.8 & 311.6 & 1.3 & $(0.3)$ \\
\hline
\end{tabular}

Notes: Multi-annual average, July 1996-November 2014. Standard errors (column 4) are for the book-to-market ratios.

All regression models used to derive the GSADF statistic include a constant. The number of lags in each equation is individually set for each sector on the basis of the BIC. The minimal window size is set according to the rule $\lambda_{0}=0.01+1.8 / \sqrt{T}$ (see, Phillips et al., 2015). $p$-values for the test are calculated via Monte Carlo simulations and using the wild bootstrap method that is suggested in Harvey et al.

\footnotetext{
${ }^{4}$ The sample period covered is chosen due to data limitations.

${ }^{5}$ Since the Israeli Stock Exchange canceled several sectors and established new ones over the years, many firms switched sectors during the review period. To keep this from affecting changes in the sectoral data, we made several adjustments.
} 
Figure 1

Sectoral book-to-market ratios
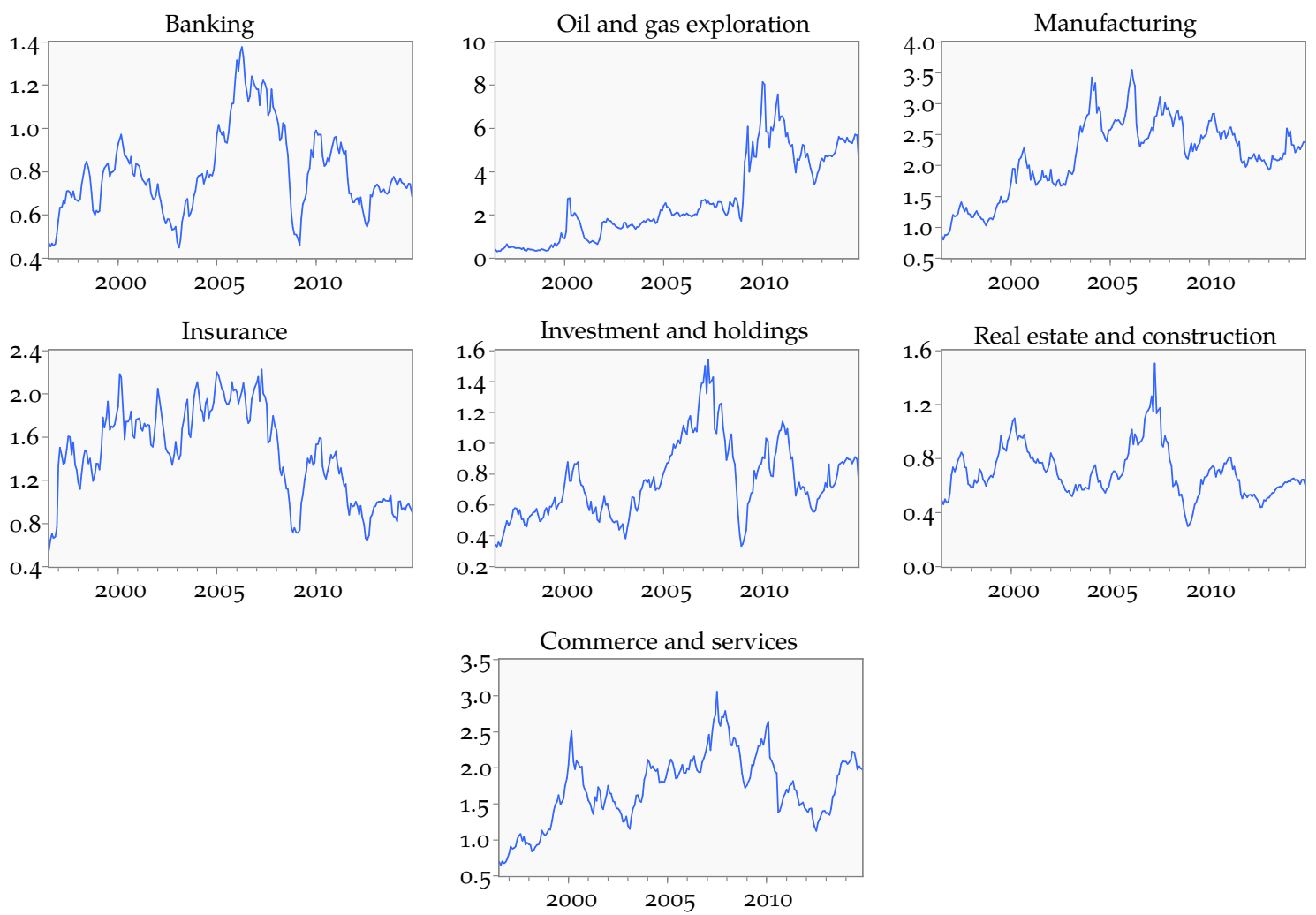

Notes: July 1996-November 2014.

(2015), which is found to be robust in the presence of potential non-stationary volatility. All simulations are conducted using the Rtadf EViews add-in (Caspi, 2015), and are based on 1,999 replications.

\subsection{Results}

Table 2 shows the results of the PSY procedure for each sectoral book-to-market ratio and at the aggregate, along with Monte Carlo (third column) and wild bootstrap (fourth column) $p$-values. The null hypothesis (nonexistence of a bubble) is not rejected in any of the seven sectors, nor at the aggregate at a significance level of at least 10 percent, with the exception of the insurance sector, whose $p$-value is 9.1 percent under the Monte Carlo simulations.

Being unable to reject the null hypothesis of no bubble precludes the need to proceed to the date-stamping procedure. Nonetheless, we feel that a visual inspection of the date-stamping procedure, shown in Figure 2, is illuminating. As we can see, the BSADF sequence does cross the threshold of rejection (dashed, 
Table 2

Results of the GSADF test for sector-level log book-to-market ratios

\begin{tabular}{lccc}
\hline Sector & GSADF statistic & \multicolumn{2}{c}{$p$-value } \\
\hline & & $\begin{array}{c}\text { Monte Carlo } \\
\text { a }\end{array}$ & $\begin{array}{c}\text { wild bootstrap }^{\mathrm{b}} \\
(2)\end{array}$ \\
\cline { 3 - 4 } Banking & & & 0.111 \\
Oil and gas exploration & 1.804 & 0.145 & 0.490 \\
Manufacturing & 1.703 & 0.172 & 0.261 \\
Insurance & 1.626 & 0.091 & 0.196 \\
Investment and holdings & 1.887 & 0.155 & 0.370 \\
Real estate and construction & 1.667 & 0.371 & 0.454 \\
Commerce and services & 1.232 & 0.102 & 0.176 \\
Aggregate & 1.856 & 0.487 & 0.523 \\
\hline
\end{tabular}

Notes: The GSADF statistic for the log book-to-market ratios for each sector and the aggregate, estimated over July 1996 to November 2014.

a The DGP for the null hypothesis is Equation (6), where $d=\eta=1$ and $\varepsilon_{t} \sim$ i.i.d. $N(0,1)$.

${ }^{b}$ Based on the wild bootstrap (Harvey et al., 2015).

red) for some of the sectors. For example, the BSADF sequence for all three financial sectors (banking, insurance, and investment and holdings) crosses the threshold and stays above it for a few months at in and around 2008 (see panel (a) of the figure). This is of course indicative of the crash that followed the global financial crisis of 2008. This demonstrates the fact that the test we use is agnostic about the direction of explosiveness: positive (bubble) as well as negative (crash) explosiveness may cause rejection. Thus, it is up to the researcher to use some discretion before calling a period a bubble. Moreover, the run-up phase of a bubble is likely to be long and gradual. Thus, "blips," i.e., short episodes where the BSADF sequence stays above the threshold, should be ruled out a priori as indicative of a bubble. 
Figure 2

Results of the date-stamping procedure

(a)

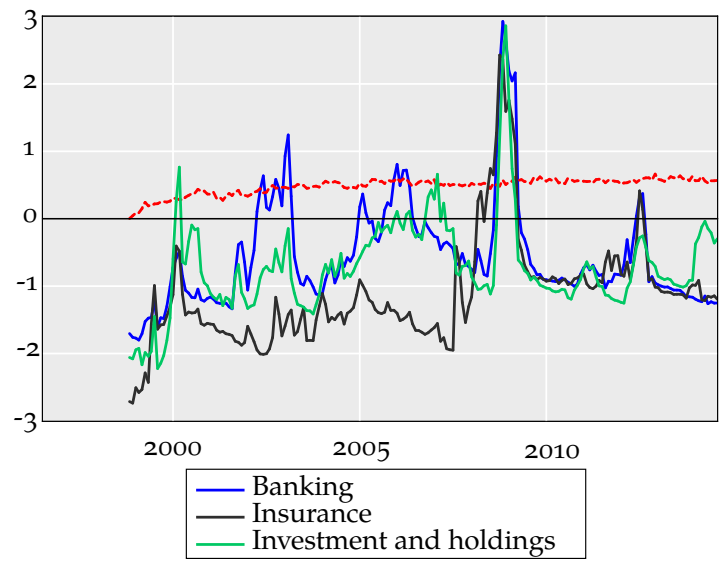

(b)

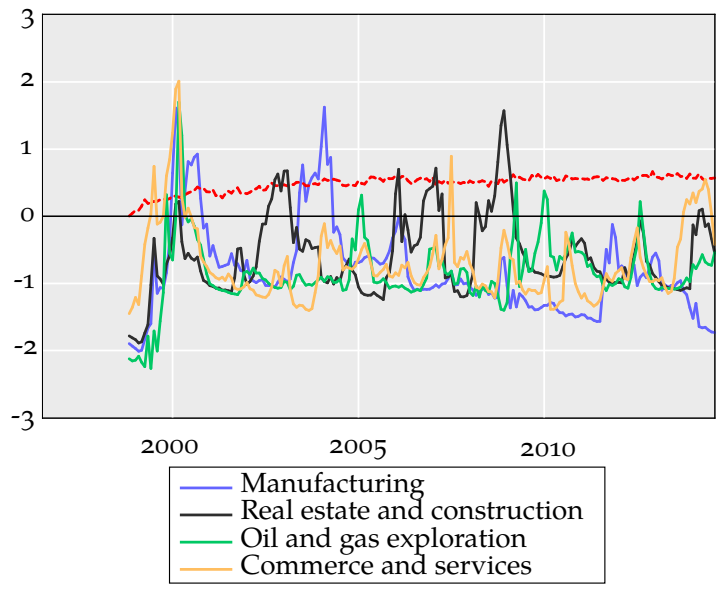

\section{Conclusions}

In this paper we show how to apply the SADF and GSADF tests for bubbles (Phillips and $Y u, 2011$; Phillips et al., 2015) in cases where dividend data are absent. Our method is based on the dynamic book-to-market ratio model of Vuolteenaho (1999, 2002), which predicts that in the presence of a bubble, the log book-tomarket ratio exhibits explosive behavior; i.e., it follows a stochastic process with a root that is greater than unity. We illustrate our framework with an empirical application to the Israeli stock market, where dividends are distributed irregularly. Using data on Israeli book-to-market ratios from July 1996 to August 2014, we find no evidence of the existence of a bubble. Our results are shown to be robust to the potential presence of non-stationary volatility. 


\section{REFERENCES}

Alexakis, C., Bagnarosa, G., and Dowling, M. (2017). Do cointegrated commodities bubble together? The case of hog, corn, and soybean. Finance Research Letters.

Campbell, J. Y. and Shiller, R. J. (1988). The dividend-price ratio and expectations of future dividends and discount factors. Review of Financial Studies, 1(3):195-228.

Caspi, I. (2015). Rtadf: Testing for bubbles with EViews. Journal of Statistical Software. Forthcoming.

Caspi, I. (2016). Testing for a housing bubble at the national and regional level: the case of Israel. Empirical Economics, 51(2):483-516.

Caspi, I., Katzke, N., and Gupta, R. (2015). Date stamping historical periods of oil price explosivity: 1876-2014. Energy Economics.

Chang, T., Gil-Alana, L., Aye, G. C., Gupta, R., and Ranjbar, O. (2016). Testing for bubbles in the BRICS stock markets. Journal of Economic Studies, 43(4):646-66o.

Christensen, C. B. and Andersen, B. L. (2015). Bubble synchronicity, migration \& spill over between countries. Working Paper.

Harvey, D. I., Leybourne, S. J., Sollis, R., and Taylor, A. R. (2015). Tests for explosive financial bubbles in the presence of non-stationary volatility. Journal of Empirical Finance, 38(B):548-574.

Homm, U. and Breitung, J. (2012). Testing for speculative bubbles in stock markets: A comparison of alternative methods. Journal of Financial Econometrics, 10(1):198231.

Jordà, Ò., Schularick, M., and Taylor, A. M. (2015). Leveraged bubbles. Journal of Monetary Economics, 76:S1-S2O.

Jordà, Ò., Schularick, M., and Taylor, A. M. (2016). Bubbles, credit, and their consequences. FRBSF Economic Letter, 2016:27.

Phillips, P. C. B. and Magdalinos, T. (2007). Limit theory for moderate deviations from a unit root. Journal of Econometrics, 136(1):115-130.

Phillips, P. C. B. and Shi, S. (2017). Detecting financial collapse and ballooning sovereign risk.

Phillips, P. C. B., Shi, S., and Yu, J. (2015). Testing for multiple bubbles: Historical episodes of exuberance and collapse in the S\&P 500. International Economic Review, 56(4):1043-1078.

Phillips, P. C. B., Wu, Y., and Yu, J. (2011). Explosive behavior in the 1990s NASDAQ: When did exuberance escalate asset values? International Economic Review, 52(1):201-226.

Phillips, P. C. B. and Yu, J. (2011). Dating the timeline of financial bubbles during the subprime crisis. Quantitative Economics, 2(3):455-491.

Vuolteenaho, T. (1999). Understanding the aggregate book-to-market ratio. DOI: $10.2139 /$ ssrn.161911.

Vuolteenaho, T. (2002). What drives firm-level stock returns? The Journal of Finance, $57(1): 233-264$. 